\title{
Peter Fleissner \\ Can religious belief systems influence technological and social innovations?
}

\begin{abstract}
:
As the author was not satisfied with the explanatory power of economic theories, in particular when they are applied to the rapid diffusion of the Internet and Internet services, he tries to analyze cultural framework conditions and processes involved that inspire inventions and innovative ideas and speed up their diffusion. He offers a scheme of thought to accompany the emergence of ideas and their reification process (Vergegenständlichung) as technical or social innovations. A few examples are given as illustration.
\end{abstract}

\section{Agenda}

Introduction

Basic hypothesis

The diffusion process

An example

Sources of inspiration and fascination

Divine Omnipotence, Money and Technology

The General J udgment and the Market

God's Omniscience and the Internet

Critical remarks

\section{Author:}

Prof. Dr. Peter Fleissner:

- vienna university of technology (TU Wien) institute of design and technology assessment, favoritenstrasse 9, A-1040 vienna, austria

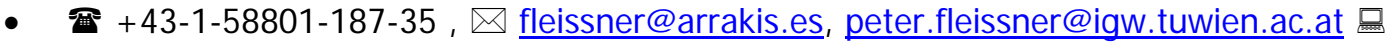
members.chello.at/gre/fleissner/default.htm, http://igw.tuwien.ac.at/zope/igw/menschen/fleissner

- Relevant publications:

- Philosophy of Culture and the Politics of Electronic Networking, 2 volumes. Peter Fleissner $\&$ Kristóf Nyíri (Eds). Innsbruck-Wien: StudienVerlag \& Budapest: Áron Kiadó 1999, Vol I 111 p. Vol II 174 p.

- Datenschutz und Datensicherheit (Data security and privacy). Peter Fleissner \& Marcel Choc (Eds). Innsbruck-Wien: StudienVerlag 1997, 417 p.

- Der Mensch lebt nicht vom Bit allein (Men shall not live by bit alone). Peter Fleissner, W. Hofkirchner, H. Müller, M. Pohl, and Ch. Stary. Frankfurt am Main etc: Peter Lang first ed. 1996, se-cond ed. 1997, 328 p. 


\section{Introduction}

As statistical evidence shows, the diffusion of the Internet is one of the most rapid and extensive of any advanced technology in history. To get an idea of the speed of diffusion one can have a look at the data of the Internet Domain Survey Host Count. In the period between 1993 and 2004 it shows an average annual growth of the number of hosts of $60 \%$ (the annual growth rates vary between $16 \%$ and $119 \%$ per year). It surpasses even the average annual growth rates of 33\% (between 1999 and 2002) of mobile phones. ${ }^{\text {ii }}$

This extraordinary expansion of Internet technology cannot be sufficiently explained just by economic parameters like rapidly declining costs stimulating demand or by the huge profits when adopting the Internet. iii Moore's empirically established Law gives an estimate for the annual decline of the costs per transistor by forty to fifty percent ${ }^{\text {iv }}$, but the speed of the Internet diffusion surpasses even the shrinking of costs. And in fact the user of the Internet does not only have to buy a computer, but has also to pay for the services of an Internet provider. And the related costs did not decline that much to explain the heavily increased demand.

Facing this lack of explanatory power, the author tried to look for another, maybe more comprehensive point of view, which could shed light on the phenomenon in question. Instead of looking for an explanation within the realm of a discipline of science or social science, which is always limited to a certain area, it might be helpful to look for a wider perspective. In an economists view, the Internet and other new technologies and social innovations can be understood in terms of inventions and innovations. If we switch to a philosophical view, innovations can be interpreted as the result of a transformation from the realm of ideas (invention) into reified reality. Already $350 \mathrm{BC}$ Aristotle has dealt with them in his book Metaphysics when he thought about ideas. He investigated the link between potentiality and actuality, and between the (original) model (Vorbild) and the (derived) image (Abbild). In contrast to processes of nature which occur automatically or self-organized, inventions and innovations are closely linked to culture and human intervention. This does not mean that they do not have to obey the Laws of Nature.

An innovation can therefore be seen as the transition of an idea (invention) from potentiality into actuality. ${ }^{v}$ In the author's opinion such a transition can be assumed as a process which is closely connected to cultural and societal subsystems, to individual expectations, preferences and life-styles.

One could understand the complete process of innovation as consisting of two parts,

1. The emergence of the idea (invention), and

2. The diffusion process (innovation).

\section{Basic hypothesis}

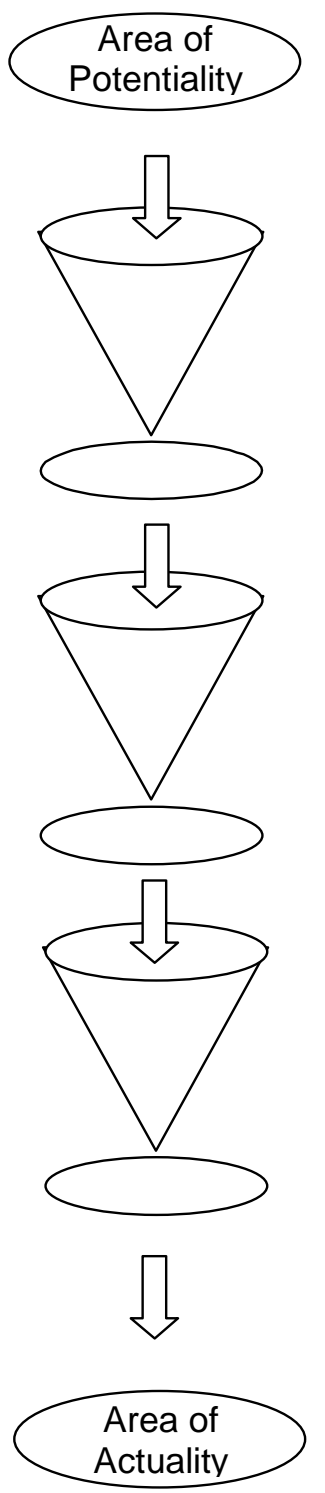

Throughout the rest of the paper the author tries to convince the reader of the usefulness of the following basic hypothesis. It consists of two parts. The first one refers to the diffusion process, the second one to the emergence of the invention itself.

a. Religious ideas stimulate the diffusion process of secular technological artefacts and make the participation in new social institutions easier. They provide for familiarity, acceptance, and eventually fascination.

b. Religious ideas contribute to the shaping of the area of potentiality. They offer concepts and structures for the invention of new technologies and social institutions and function as sources of inspiration.

Of course, this hypothesis has to be supported by empirical facts before one can accept it. The author is aware of the methodological problems related to a "proof" of such fuzzy hypothesis. Instead of providing a stringent proof 
which cannot be given here the author illustrates it by examples.

\section{The diffusion process}

Let us deal with the diffusion process first and postpone the discussion of the emergence of the idea for the moment. We can assume that the idea already exists in the area of potentiality. The diffusion process can be understood as if the invention - before it arrives at the area of actuality has to pass various tests or filtering processes (see figure at the left side). The tests link potentiality to actuality. For analytical convenience each test should be associated with a specific cultural/societal area for which questions can be formulated, relatively independent of others. If the idea passed one test, it can go on for the next one. To bring an innovation into actuality means that the idea has passed all tests successfully.

The definition of the area and the circumstances how and where the test has to be applied is essential for the applicability and usefulness of these considerations. It seems important that the tests reflect central conditions of reality, and do not ignore essential aspects. On the other hand, it is not useful and even not possible that tests reflect every aspect of reality. It is a kind of art to define the adequate and appropriate tests in a skillful way. Each test will refer to a certain stratum which is relevant for the reification of the idea. There are many candidates, often corresponding to certain disciplines of social sciences: cultural studies, political science, sociology, macro- and microeconomics, consumer preferences etc.

If the idea did not pass a test, the "area of potentiality" (Möglichkeitsfeld ${ }^{\mathrm{vi}}$ ) wherein the idea was located, is reduced to impossibility. The idea cannot be carried out.

In the positive case, when the idea passed the test, the "area of potentiality" is also restricted, but not completely. There is still room for manoeuving to continue with the next test on the basis of a "smaller vii", but not completely empty area.

If we add a time dimension to the analysis, we have to take into account varying framework conditions of the testbed. If, for instance, the price of a technological artefact decreases over time, the diffusion process might be speeded up. But there is more than just economic issues. If people are not familiar with a new technology or the function and meaning of an institution, there will be only a small probability that they will adopt them.

To overcome the difficulties in the course of the diffusion process, frequently "Leitbilder" are used to produce familiarity. Often they cosist of catchwords (e.g. "information highway" or "global village"), which create mental bridges from the familiar past experience to the unknown future. ${ }^{\text {viii }}$ But familiarity can also stem from other sources, images and metafors which are transported in the cultural tradition. If there is familiarity, it also increases the acceptance of the invention. If, in addition, the invention is able to create fascination (fascination of a single fact emerges if this fact can be immediately connected mentally to one or more of the "higher" cultural values), the speed of diffusion will increase even more. Fascination will stimulate the demand and/or assure the stability of a social innovation because everybody would like to participate in it.

\section{An example}

Let us illustrate the described concepts by an example: the gasoline-powered automobile. When on $29^{\text {th }}$ January 1886 Karl Benz presented the first auto-motive car in the streets of Mannheim, Germany, it was a triumph of engineering. Benz's idea reflected the preference of mechanical engineers for mechanical stability of a structure resting on three points only (compared with the statically over-determined four point construction), so he proposed a car with three wheels, but he did not adequately foresee the reactions of possible customers: Benz could not sell even one single car. Probably people were simply not used to three wheel vehicles, because the majority of the traditional horse-buggies had four wheels. As a consequence they could not accept a three wheel car.

But Benz was able to learn from this flop. Within seven years he redesigned the car, and 1893 he come up with "Victoria", a new high-tech version of excellent performance, this time with four wheels. But still, there was once again a problem: the price was prohibitively high to sell more than a few items. Benz had to undergo another learning process that finally lead to success, this time on the economic level: With "Velo", a smaller car of rather oldfashioned design, with a weak motor of only $1.5 \mathrm{hp}$ in the rear and a belt-drive, but with the low price of only 2000 Mark, between 1884 and 1902 Benz sold 1200 items, unheard in those times. 
What can we learn from this example? We can identify the following three items:

1. There are one or more reference systems where the invention got its inspiration from.

2. The first test to be passed was the acceptance of the specific design by the consumer.

3. The second test to be passed was the acceptance of the price by the customers.

Because of the masses of cars in our roads the situation of today has become more complex. Many of us are convinced that the automobile produces more and more negative effects, on human beings and the environment. The number of deadly accidents per year is similar to the losses of people in wartime, the big cities are jammed by cars, the environment is damaged, and people have to breathe poison even if they are not in direct contact with any vehicle.

The above example indicates that for any invention of a new type of a car additional tests should be designed in such a way that the negative effects are reduced or neutralized, e.g. tests related to exhaust fumes, fuel consumption, safety, and other measures to prevent environmental problems (like asbestos-free tires etc.).

\section{Sources of inspiration and fascination}

Instead of going into further details on how to design the tests, the author focuses now on the second aspect of the hypothesis, the source of inspiration of an invention. While there might be various reasons and motivations for the invention, either to create a solution to an existing problem, or to get rid of an existing constraint, or to improve an already existing process or product, the area of potentiality is not limited to those types of innovations. It is also possible to invent completely new products or processes, technological or social innovations unseen in history before. Where are they inspired from?

From this position it is justified to look for really novel products, processes or institutions in human history, on the one hand, and for fantasies, images, metaphors, myths, fairytales, heroic sagas or legends prevalent in the cultural context of the inventor on the other. Maybe one can find some coincidence or structural equivalence which could mean that there is some connection between the two?

If we go for fantasies first, we should not look for individual ones, but for the ones socially shared, and not for those created recently, but for the ones with an early origin in history. ${ }^{\text {ix }}$ The most elaborated fantasies can be found in belief systems with a long tradition, because theologians have worked on them for centuries. But the belief systems should be still alive: If they already died out it becomes difficult to understand their content. All these conditions are fulfilled by the three religions in the Abrahamic tradition, Judaism, Christianity, and Islam. The most widely spread religions in the world ${ }^{x}$, in Europe, and in the United States ${ }^{x i}$ are the ones in the Christian/J ewish tradition. So it would not be wrong to investigate the content of the Bible and its interpretation by theologians and look for metaphors and images within this belief system.

In my opinion one would not do justice to the role of religion if we follow the opinion of Jakob Burkhardt, one of the famous German historians of the $19^{\text {th }}$ century. He allocated the creative function in culture to technology, arts and literature, while the state and religion were seen as repressive institutions. Although his position reflects reality to a certain degree, in my opinion it does not show the full picture. ${ }^{x i i}$ To paint a more comprehensive picture of religion in a longer-term perspective, we should not only deal with its repressive function, but also look for the structure of thought, the images and ideas created by it and their effects. ${ }^{\text {xii }}$

Let us take, for example, the concept of God as it emerged from monotheistic religions, or the myth of paradise, redemption, life after death, the origin and the end of the world: All these images (or more precisely the wishes and hopes behind them) reached out much farther than just to the religious community. They inspired arts and science. On their ground philosophical and political systems were developed which became antagonists of the religious institutions, but also copied some of their features. Here is an example taken from history: Although the citoyens of the French Revolution had declared atheism as their favorite ideology, they could not evade the temptation to warship gods. In the year 1794, only a few days before Robespierre was sentenced to death, he received divine honors in an excellent liturgy.

Let us now ask for the core concepts of religious tradition which are still alive and therefore 
worthwhile to deal with them. A first answer we find at Ludwig Feuerbach, who in 1841 wrote in "The Essence of Christianity": "Religion is the dream of the human mind. But even in dreams we do not find ourselves in emptiness or in heaven, but on earth, in the realm of reality; we only see real things in the entrancing splendor of imagination and caprice, instead of in the simple daylight of reality and necessity $^{\text {xiv }}$... We have shown that the substance and object of religion is altogether human; we have shown that divine wisdom is human wisdom; that the secret of theology is anthropology; that the absolute mind is the so-called finite subjective mind". xv 1845, in his famous "Theses on Feuerbach" Karl Marx criticized Feuerbach: "Feuerbach resolves the religious essence into the human essence. But the human essence is no abstraction inherent in each single individual. In its reality it is the ensemble of the social relations". "xvi Marx concluded by the famous statement: "The philosophers have only interpreted the world, in various ways; the point is to change it." Today, after the implosion of Socialism, this imperative is as much needed as before, the problem I see is the lack of a convincing alternative.

If it is true that religion can be understood with Feuerbach as a dream of the human mind, it should be interesting to identify the specific content of the dream. Following Sigmund Freud, dreams are a form of fulfilling suppressed wishes. By his method of Dream Interpretation one could detect the underlying structure of repressed emotions, aspirations and obstructed instinct drives, which will reify itself not only in dreams, but also in the purposeful practice of everyday life. For a sound scientific investigation this practice should be identified and should be compared with the underlying wishes.

\section{Divine Omnipotence, Money and Technology}

A sketch of the rational description of the connection between "condition humaine", religious images and social/technological innovations can now be given as follows: The individual fantasies on Omnipotence of early childhood on the one hand, and the presentiments of the power of humankind generate in specific societies a fantasy of an external institution independent of human beings, which at the same time allows to answer the question of the where from and the where to: An almighty God, creator of everything, assisting his allies in all their fights and giving them redemption from Evil.

In the Old Testament God shows many features of a jealous, sometimes brutal chief - mimicking the centre of social power of livestock breeding communities. In one way God is an upward projection of the social organization, on the other hand God's characteristics negate the limitations and restrictions of the human condition. In the New Testament in the face of the Roman Empire, the view becomes more universal, the reference society is no longer the tribes of J ews, but the whole known world - an interesting synchronicity between fantasy and history. God becomes upgraded from the God of Israel to the God of all human beings on Earth. The principle of revenge is no longer the ruling principle, but the principle of love and forgiving. In St. J ohn's Apocalypse God becomes the founder of a New Jerusalem, who shall wipe away all tears (from the eyes of the just ones) and the creator of a New Paradise, which will replace the vale of tears. These images and wishes were passed on over centuries and still provide a framework where we can anchor our fantasies. They are not only fantasies; at the same time they represent potentials of societal developments. They anticipate what could happen in the future and produce a field of wishes, motivations and thoughts which might define and stimulate fields of actions which could transform reality.

From there God's Omnipotence could be interpreted as the veiled description of the associated power of human beings. Can there any correspondence be found to a worldly institution of the collective action of the people? Of course, the immediate response could be the mirror of God's power in the power hierarchies on Earth, of emperors, kings, statesmen, bosses, etc., but more can be said. There is also a fascinating phenomenon which is much younger than institutional hierarchies: Money. It allows its owners to exert social power. It is very practical, because everybody is in a position, to carry around in their pockets bits and pieces of the Divine, the power of joint social activities, to be activated via human labor. It can easily be transformed into social power or its results. The major advantage: One does not have to wait for the Last Day. ${ }^{\text {xvii }}$

Money is a societal construction which represents societal wealth and power in reified form as the "generalized commodity". Money has a double existence, on the one hand as material (coin or paper money) or energetic (electronic money) representation, and as an abstract-general symbol on the other. Without the belief of the people (this 
belief represents a secular belief system) in the value of the coins, sheets of paper or electronic representations of money, selling and buying, saving and spending in everyday life would not work.

While money covers the general ability to exert power for everybody who owns it, the act of buying is performed to meet a specific need by a commodity or service, e.g. the car allows for prestige and mobility, the TV-set satisfies the need for entertainment etc. Consumer goods and services produced via technology enable the user to meet specific needs or to have pleasure. Once again, religious images can provide us with triggers and motives to develop new products or services. For example, geriatric services gain by the dream of eternal life, the miracle healings of the New Testament inspire the medical professions, and God's creative power is imitated by the cloning of Dolly.

\section{The General Judgment and the Market}

A nice collection of religious ideas can be found in Roman Catholicism, section eschatology, the theological teachings on the Last Things. According to the theologians Karl Rahner and Herbert Vorgrimler "one uses to enumerate the various partial moments of the one radical finality... of the human being as follows: Death, individual Judgment, Purgatory, Heaven, Hell, Resurrection of the Flesh, General Judgment, New Heaven and New Earth". These Last Things should not be seen "as an anticipating report of events which will happen 'later', but as a preview for human beings to enable them to do their necessary spiritual decision in freedom based on a situation which is defined by the "heilsgeschichte" (salvation/saving history) and the event Christ towards the final completion of their own, already eschatologically formed existence". xviii I can see here elements of a religion tightly linked to redemption groping for a better future. The search for the pathway towards such a future is not restricted to Christianity, but is the core question of social utopias. Also the vision of a classless society intended by Socialism was nourished by similar wishes.

One of the above mentioned "Last Things" shall now be investigated in more detail: The General J udgment. In my interpretation the concept is based on the longing of human beings for justice, but a justice which is not created by human beings. It directly emanates from God, a powerful external force, independent of human beings, but judging them on their deeds. "And all the nations will be gathered before Him; and He will separate them from one another, as the shepherd separates the sheep from the goats;" (Matthew 25:32). So far the religious image can be described.

If we look for analogue structures in our secular reality we can identify several prototypes like the authoritarian father, the teacher, the judge etc. All of them are based on individuals. They are so to say individual reifications of God. But there is one exception which is impersonal: The market. It shows an analogue structure like the General Judgment. The market rewards the "good" ones and punishes the "bad" ones in an impersonal way. In fact, it provides a kind of justice, assessing the deeds of people.

But the transformation from Heaven to Earth has also its cost: As a consequence, the meaning of the key terms is modified, while keeping the structure invariant. "Good" now means "profitable"; "bad" transformes into "loss-making". xix

The "good" ones inherit the Kingdom of Heaven, meaning on Earth that they can continue their economic actions, well provided with profit, while the "bad" ones become expelled from the market and have to leave the economic arena. In Heaven all people are equal before God; on Earth they are equal before the market. Neither gender, nor appearance, neither age, nor color of skin is anymore important. The only thing what counts are the deeds. No human being announces any judgment; the judgment is given by an authority independent of human beings, nevertheless the judgment of the market is binding and fateful.

But there are not only effects for the individual; there is also the earthly promise of the Heavenly Jerusalem for humankind: As we can learn from the belief of neo-liberals, the local dynamics of the market and its effectuating function will lead us to happiness and well-being for everybody in the global economy.

\section{God's Omniscience and the Internet}

Observers of the contemporary social fabric emphasize the increased fragmentation, lack of cohesion and social coldness of Western societies. This can be seen partially as a result of the 
contradictory and conflicting transitions from mainly community based, small scale, informal relations between people towards large scale, abstract, rational and calculated relations to modern society. $^{x x}$ On the level of communication, communities are characterized by local and direct face-to-face communication, while in modern societies there is a definite need for communication and interaction between distant individuals. In such a situation the divine features of Omnipresence and Omniscience get new actuality, and modern technology can respond to this need to a certain degree.

While TV offers pictures from all over the world (and also allows a view into micro- and macro worlds) to everybody who has got access to a TV set, and by that brings us closer to Omnipresence, the freedom of choice of the individual is still limited and depends on the supply which is controlled by the demand of the many. Individual TV on demand only exists on a reduced basis (e.g. web cams with remote control). The Internet, however, allows individual access to and exchange of texts, pictures, voice and videoresources, and therefore enables the customized interactive appropriation and diffusion of information according to the needs of the individual. Existing language barriers are reduced by automated translation programs and make sense if they are used in an intelligent way. People are not only in a position to participate in the information pool of humankind (maybe only its more wealthy strata); they function also as information providers. The recent project of an Internet-Encyclopedia seems to represent an interesting example which had a wellknown predecessor in the dawn of the French Revolution.

Around 1750 the Encyclopedia (full title: Encyclopedia, or a Systematic Dictionary of Science, Arts, and the Trades) edited by Denis Diderot (and by Jean d'Alembert for the mathematical parts) became famous because it tried a summary of all the available knowledge on the workings of the known world. It took about 20 years on its way to becoming a 28-volume treatise on human affairs, but unfortunately it was never completed. The Dictionnaire, as it was called, boldly told the average man that he could know what only God, kings, emperors, and their lieutenants were supposed to know. More than a summary of all contemporary knowledge, it served as a manifesto for a new way of looking at the world. It foreshadowed the egalitarian attitudes which were to undermine the old aristocratic order. It suggested that anyone should have access to rational truth. In that sense it was a profoundly revolutionary document, but for this very reason also controversial - principally because many of its articles reflected the impious attitudes of its contributors like Voltaire and Rousseau, many of whom were participants in the rationalist movement known as the Enlightenment.

Recently, we can see a revival of Diderot's dream: Wikipedia is a very successful project of volunteers to offer valuable knowledge on the World Wide Web to the general public, and all this free of charge. ${ }^{\mathrm{xxi}}$ It started in 2001 and contains now (6 June 2004) 279.653 articles from nearly every area of knowledge. With 60 million words it has already quantitatively surpassed Encyclopedia Britannica which contains "only" 56 million words. Also since spring 2003 the hits on Wikipedia surmount the ones on Encyclopedia Britannica on the Internet. Wikipedia also has a German branch ${ }^{\text {xxii }}$ which is smaller than its English original.

Different from all the other encyclopedias before, the fascinating idea behind the project is the possibility to influence and change the entries in the websites, directly and interactively, by really everybody who likes to contribute. And all this can be done without any human editor in chief. Even the founders of Wikipedia, Jimmy Wales and Larry Sanger, understand themselves as ordinary participants. And there is hope for solidarity: When Wikipedia in December 2003 experienced a breakdown because of too many hits, on a single online-request for donations 20.000 US Dollars could be collected.

This project proves that with new technologies and new ways of cooperation in groups in principle and in practice efficient tools can be developed which might be used by everybody and let them participate in the global knowledge pool - and all this free of charge. ${ }^{\text {xxiii }}$.

As Wikipedia illustrates a tendency towards Omniscience for humankind, this is not the end of the story. More can be expected: With the high diffusion rates of the Internet and the increase of its capacity not only access to information of all kind becomes more and more possible on a global scale, but also the cooperation of people in virtual spaces. In a certain meaning of the term, Omnipresence becomes possible. While people are still not able to be physically present wherever they like, the Internet allows them having tele-voice, tele-eyes, tele-ears $^{\text {xxiv }}$ and other kinds of tele-sensors at nearly any place of the world. If there is a direct link to the virtual space, the physical location does no 
longer matter. Already now one can participate in interactive computer games as part of an international online-community of thousands of people. Computerized cooperative work allows the collective design of complex molecules, of bodyworks of cars or robots, irrespective of the physical location of the workers.

With the emergence of the "information society" an additional piece of the prophecy of the serpent to Adam and Eve will be fulfilled: "You will be as God" (Genesis 3:5). Unfortunately, up to date not all of God's properties fell down to earth yet: still mercy, love and wisdom are missing.

\section{Critical remarks}

The author is aware that he is walking on shaking ground. By no means, this paper established a strict proof of the hypothesis in the beginning. Many questions remain unanswered. Only a few are mentioned: What is the relationship between the needs and wishes of everyday life and the images and teachings of religious belief systems? The paper focused on religious fantasies as if they were the only moving ideas in the background of innovations, but in fact the situation is more complex than that. Maybe actual everyday needs are the primary mover, and religious fantasies are just an expression of them? Is there more to be found when we look for specific historic periods and their corresponding religious fantasies? Much more work could be done, but this is left to the reader.

Proceedings of the symposium "Localizing the Internet. Ethical Issues in Intercultural Perspective" sponsored by Volkswagen*Stiftung*, 4-6 October 2004, Zentrum für Kunst und Medientechnologie (ZKM, Karlsruhe) 
Figure 1

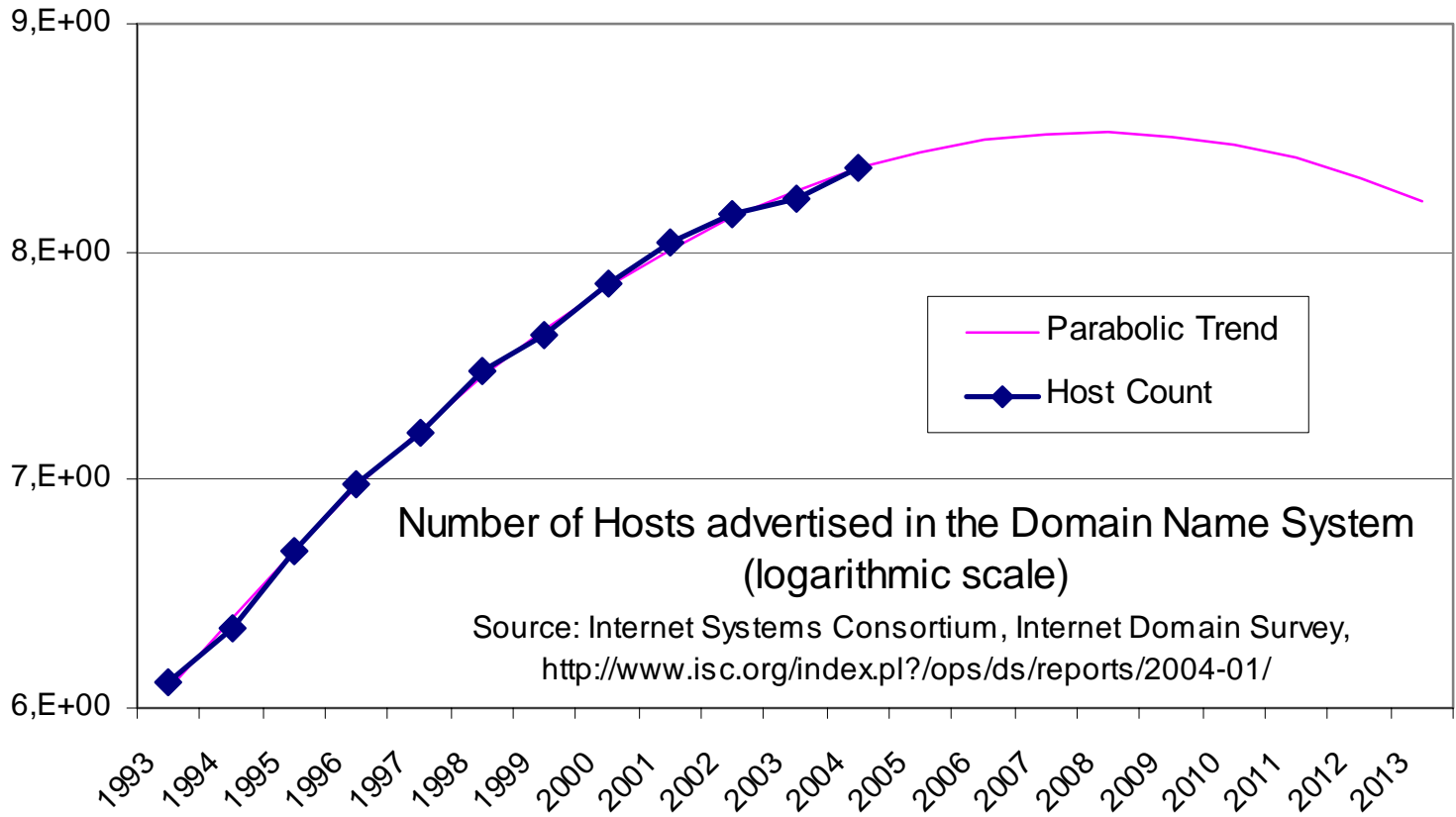

i On the other hand it seems interesting to look for the trend. If one applies regression analysis to the data using a quadratic function of time on the logarithmic values one ends up with a saturation level of 335 million hosts already in the year 2008 (compared to 233 million in January 2004 - see figure below). If one uses a logistic curve on the original data, $90 \%$ of the saturation level of 330 million will be reached in 2008. These are some indications that growth will not continue at the same speed for the decades to come. (Figure 1)

iihttp://www.weforum.org/pdf/Gcr/GITR_2003_2004 /Progress Chapter.pdf (12/07/04). The reader should be aware that the number of hosts is not the same as the number of users, and also that not all the domains counted are really available via the Internet. The number of users increased sharply: In the second half of the 90ies 50 to 60 million users were counted. In 2004 the estimates are in a range between 400 and 600 million (Der Standard, 16 J uly 2004).

iii In particular for small and medium sized enterprises only a few of the many start-ups survived (Latzer, M. and S. Schmitz, Die Ökonomie des eCommerce, Metropolis, Marburg 2002, p. 182)

iv http://www.intel.com/intel/museum/25anniv/hof/m oore.htm (14 May 2004)

v The author uses "actuality" as the appropriate term for the implementation of an innovative idea. "Reality" is not used because ideas themselves are also part of reality (of the mental one).

vi The term is inspired by Herbert Hörz who thirty years ago developed the concept of the "statistical law" (see e.g. Hörz, H., Wissenschaft als Prozess, Berlin 1989, pp.38-40). „Das Möglichkeitsfeld umfasst die mit der Tendenz des Systemverhaltens verbundenen wesentlichen Möglichkeiten des Elementverhaltens, die sich bedingt mit einer bestimmten Wahrscheinlichkeit verwirklichen." (p. 110)

vii The space used to describe the area of potentiality will be made of qualitative variables. In areas of economics or in scientific and technical investigations also quantitative variables can be used. 
viii P. Fleissner, W. Haidweger, and E. Horányi, The Advent of the Information Highway in: P. Fleissner and J.C. Nyíri (eds), Philosophy of Culture and the Politics of Electronic Networking, Innsbruck-WienBudapest 1999, 2 Volumes, Volume 1, pp. 67-99, p.75 ff.

ix At http://philtar.ucsm.ac.uk/encyclopedia/europe/ (13 July 2004) one can see that the best candidates are the three book-religions, Judaism, Christianity and Islam (the youngest one, since $711 \mathrm{CE})$.

At

http://www.adherents.com/Religions By Adheren ts.html one can find that $33 \%$ of the world population are Christians, 22\% Muslims, $15 \%$ Hindus, $14 \%$ non-religious, and $6 \%$ Buddhists.

${ }^{x i}$ In the US there are 56\% Protestant; 28\% Roman Catholic; $2 \%$ J ewish; $4 \%$ other; $10 \%$ none.

xii It seems to be biased in the same way as was the pessimistic view of technology in the second half of the $20^{\text {th }}$ century which came into being under the impression of the nuclear bombs on Hiroshima and Nagasaki, exploding nuclear reactors, greenhouse effects and other destruction of the natural environment. This view neglected the positive potentialities of modern technology.

xiii In a similar approach one can interpret the action structures and functions of early magic practices of humankind as fantastic predecessors of modern technology, or alchemy as germs and seeds of modern chemistry. Such early practices created in the minds of people the basis for modern science.

xiv Feuerbach, L., Das Wesen des Christentums, Reclam, Leipzig 1957, German original p. 49, English translation http://www.marxists.org/reference/archive/feuerb ach/works/essence/ec00.htm

xv ibid. German original p. 371, English translation http://www. marxists.org/reference/archive/feuerb ach/works/essence/ec27.htm

xvi Marx, K., Engels, F., Ausgewählte Werke, Progress Verlag, Moskau 1971, p. 27, English translation:

http://www. marxists.org/archive/marx/works/184 5/theses/theses.htm

xvii Already in the Old Testament the competition between God and societal wealth reified in noble metal was expressed in the Dance around the
Golden Calf. At that time God won the victory, but after Nietzsche we can no longer be sure if $\mathrm{He}$ is still alive.

xviii Rahner, K., H. Vorgrimler, Kleines Theologisches Wörterbuch, Herder Verlag, Freiburg im Breisgau 1961, p. 100

xix Marx and Engels characterized the transformation in the following drastic way: "The bourgeoisie, wherever it has got the upper hand, has put an end to all feudal, patriarchal, idyllic relations. It has pitilessly torn asunder the motley feudal ties that bound man to his "natural superiors", and has left no other nexus between people than naked self-interest, than callous "cash payment". It has drowned out the most heavenly ecstasies of religious fervor, of chivalrous enthusiasm, of philistine sentimentalism, in the icy water of egotistical calculation. It has resolved personal worth into exchange value, and in place of the numberless indefeasible chartered freedoms, has set up that single, unconscionable freedom -- Free Trade. In one word, for exploitation, veiled by religious and political illusions, it has substituted naked, shameless, direct, brutal exploitation." See K. Marx \& F. Engels, Manifesto of the Communist Party,

1848 http://www.anu.edu.au/polsci/marx/classics/manif esto.html

$\mathrm{xx}$ See Ferdinand Tönnies, Gemeinschaft und Gesellschaft. Grundbegriffe der reinen Soziologie. Dritte durchges. Aufl. Berlin 1920; Arno Bammé, (ed) Ferdinand Tönnies - Soziologe aus Oldenswort. München, Wien: Profil Verlag 1991; Max Weber, Soziologischen Grundbegriffe. Tübingen: UTB-Taschenbücher 541. Reprint of 1921, 1984, pp. 69-72; Peter Ruben, Gemeinschaft und Gesellschaft - erneut betrachtet. H.v. Schorkowitz (ed) Ethnohistorische Wege und Lehrjahre eines Philosophen. Festschrift für Lawrence Krader zum 75. Geburtstag. Frankfurt a. M.: Peter Lang. 1995, pp. 129-148; Peter Fleissner, Von der Stammesgemeinschaft zur Globalgesellschaft - und zurück? (From tribal community to global society - and back?). In Alfred von Liechtenstein (ed.) Internet und Öffentlichkeit. Wiener Vorlesungen Konversatorien und Studien 13. Wien: WUV Universitätsverlag, 2002, pp. 83-96.

${ }^{x x i}$ see http://en.wikipedia.org
xxii see http://de.wikipedia.org 
xxiii see Die Presse, 5 June 2004, hightech\&automotor. Of course there is no free lunch: Wikipedia is limited to those with Internet access and the know-how to interact with it.

xxiv and more and more also mobile communication 